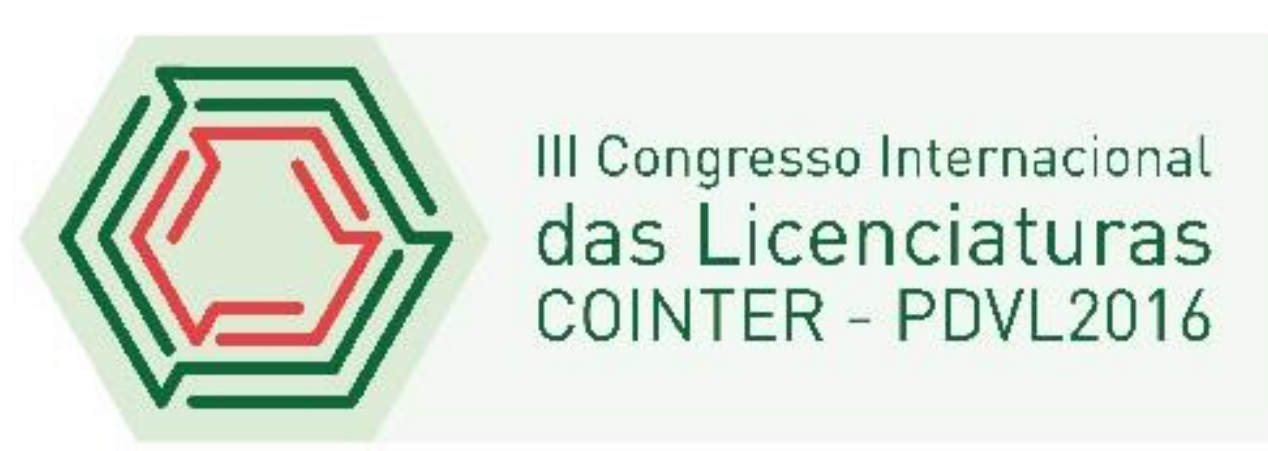

\title{
OS DESAFIOS ENFRENTADOS PELOS PROFESSORES QUANDO DA UTILIZAÇÃO DE PRÁTICAS PEDAGÓGICAS INOVADORAS NO ENSINO FUNDAMENTAL
}

Apresentação: Comunicação Oral

Rosélia Maria de Sousa Santos ${ }^{1}$; José Ozildo dos Santos Segundo ${ }^{2}$; Vanessa da Costa Santos ${ }^{3}$; Leandro Machado da Costa ${ }^{4}$; José Ozildo dos Santos ${ }^{5}$

\section{OS DESAFIOS ENFRENTADOS PELOS PROFESSORES QUANDO DA UTILIZAÇÃO DE PRÁTICAS PEDAGÓGICAS INOVADORAS NO ENSINO FUNDAMENTAL}

\begin{abstract}
Resumo
Trata-se de um estudo do tipo descrito com descritivo com uma abordagem qualitativa, realizado no município de Patos, no Estado da Paraíba, tendo como campo de pesquisa uma escola da rede pública estadual. No contexto da sala de aula, deve-se recorrer às estratégias metodológicas que possam ser reconhecidas e qualificadas como inovadoras e capazes de despertarem o ser pensante, o ser crítico, o ser criativo existente em cada educando. Assim, para desenvolver uma aula de forma criativa, o professor pode utilizar-se de vários métodos, motivando o aluno para a aprendizagem, provocando-o a participar do processo educativo, de forma a criatividade pode ser vista como sendo algo faz a diferença e sala de aula, produzindo o envolvimento de todos os alunos, criando novas situações de aprendizagem. Através da presente pesquisa pode-se constatar que o processo de ensino aprendizagem na Escola Estadual de Ensino Fundamental Coriolano de Medeiros, vem se desenvolvendo de forma regular e que os professores da referida escola, ao desenvolverem suas aulas, tentam estabelecer uma conexão com a realidade vivenciada em seu dia a dia pelo aluno. Todos entrevistados sabem qual a importância da criatividade no contexto da sala de aula e possuem uma ideia formada sobre o que é um professor criativo.
\end{abstract}

Palavras-chave: Processo de Aprendizagem. Práticas Inovadoras. Criatividade.

\section{Introdução}

O processo de aprendizagem, na atualidade, deve ser repensado no que diz respeito às articulações teóricas e práticas, a fim de garantir o acesso ao conhecimento sistematizado e à prática pedagógica, priorizando os diferentes níveis de ensino e tipos de saberes.

\footnotetext{
${ }^{1}$ Licenciatura em Letras, IFPB, E-mail: roseliasousasantos@ hotmail.com

${ }^{2}$ Licenciatura em Pedagogia, UFRN, E-mail: ozildosegundo@ hotmail.com

${ }^{3}$ Letras, IFPB, E-mail: nessacosta1995@ hotmail.com

${ }^{4}$ Agroecologia, IFPB, E-mail: leandropl@hotmail.com

${ }^{5}$ Mestre, Universidade Federal de Campina Grande, E-mail: jose.ozildo@ufcg.edu.br
} 
Para isso, é necessário mobilizar ações e métodos alternativos que auxiliem tal processo, criando, assim, um espaço para o fazer pedagógico. Na construção desse espaço, o professor pode e deve utilizar-se da criatividade, desenvolvendo os mais diferentes recursos pedagógicos, transformando a sala de aula num local onde se produza uma aprendizagem significativa (COSTOLDI; POLINARSKI, 2009).

Para promover uma melhor aprendizagem no ensino fundamental I, o professor precisa ser criativo e inovador. Ele precisa saber inovar constantemente a sua prática pedagógica, simplesmente porque na maioria das escolas pública, praticamente, não existem recursos para se promover uma boa aula.

A realidade brasileira mostra que a maioria das escolas públicas é desprovida de recursos pedagógicos. Não possui laboratórios técnicos e nem de informática, sequer possui bibliotecas. Apenas o livro didático é disponibilizado ao professor e ao aluno, cabendo ao primeiro a difícil missão de produzir uma aprendizagem significativa.

Assim sendo, sem recursos pedagógicos e tecnológicos o professor, principalmente, aquele que atua no ensino fundamental, é obrigado a ser criativo, a fazer da criatividade algo sempre presente em sua sala de aula, na busca de chamar a atenção do aluno para o conteúdo que precisa ser trabalhado. Noutras palavras, ele precisa saber desenvolver sempre práticas pedagógicas inovadoras, capazes de motivarem seus alunos e produzirem uma aprendizagem significativa.

A maioria das escolas públicas brasileira não possui recursos didáticos para auxiliar no processo de ensino aprendizagem, essa falta passa a constitui-se numa dificuldade à educação, limitando todo o processo educativo que se pretende desenvolver em sala de aula.

Para superar os obstáculos vivenciados em sua sala de aula e proporcionados pela falta de recursos e materiais pedagógicos, o professor precisa, além da formação, ter competência, criatividade e ser aberto para aprender. Ele precisa saber conhecer/identificar as limitações de seus alunos para assim, selecionar as melhores metodologias que deverão ser utilizadas em sala de aula, utilizando-se sempre de práticas pedagógicas inovadoras.

O presente trabalho tem por objetivo avaliar os obstáculos enfrentados por aqueles professores que tentam inovar o processo educativo, objetivando uma aprendizagem significativa.

\section{Fundamentação Teórica}

O processo de ensino-aprendizagem é algo muito dinâmico, no qual podem surgir vários desafios, que se não contornados, trazem prejuízos ao seu desempenho. 
De acordo com os Parâmetros Curriculares Nacionais (BRASIL, 1997, p. 22), para que ocorra uma boa aprendizagem:

[...] é necessário que sejam exploradas a aprendizagem de metodologias capazes de priorizar a construção de estratégias de verificação e comprovação de hipóteses na construção do conhecimento; a construção de argumentação capaz de controlar os resultados desse processo; o desenvolvimento do espírito crítico capaz de favorecer a criatividade e a compreensão dos limites e alcances lógicos das explicações propostas.

Assim, é fundamental que o professor, antes de elaborar situações de aprendizagem, investigue qual é o domínio que cada criança tem sobre o assunto que vai explorar, ou seja, em que situações algumas concepções são ainda instáveis, quais as possibilidades e as dificuldades que cada criança enfrenta sobre este ou aquele conteúdo.

Afirmam ainda os Parâmetros Curriculares Nacionais (BRASIL, 1997, p. 38), que:

A aprendizagem é condicionada, de um lado, pelas possibilidades do aluno, que englobam tanto os níveis de organização do pensamento como os conhecimentos e experiências prévias, e, de outro, pela interação com os outros agentes.

Para que ocorra uma aprendizagem significativa, o professor precisa entender que os conhecimentos que as crianças possuem, adquiridos fora da escola, não devem restringir-se a eles. Pois, o papel da escola e do professor é de ampliar esse universo de conhecimentos e oferecer condições para que elas estabeleçam vínculos entre o que conhecem e os novos conteúdos que vão construir, possibilitando uma aprendizagem significativa.

A aprendizagem é o processo de alteração de conduta de um individuo, seja por condicionamento operante ou por experiência, de uma forma razoavelmente permanente. Nesse processo, as informações podem ser absorvidas através de técnicas de ensino ou até pela simples aquisição de hábitos.

Abordando a construção do processo de ensino-aprendizagem, os Parâmetros Curriculares Nacionais (BRASIL, 1997, p. 91), afirmam que:

A aprendizagem é um processo de mudança de comportamento obtido através da experiência construída por fatores emocionais, neurológicos, relacionais e ambientais. Ela é o resultado da estimulação do ambiente sobre o individuo já maturo, que se expressa, diante de uma situação-problema, sob a forma de uma mudança de comportamento em função da experiência. 
É comum as pessoas restringirem o conceito de aprendizagem somente aos fenômenos que ocorrem na escola, como resultado do ensino. Entretanto, o termo tem um sentido muito mais amplo: a aprendizagem se refere os aspectos funcionais e resulta de toda estimulação ambiental recebida pelo individuo no decorrer da vida. Desta forma, percebe-se que a aprendizagem é um processo contínuo. No entanto, cada indivíduo tem seu ritmo próprio de aprendizagem que, aliado ao seu esquema próprio de ação, irá construir sua individualidade.

Observam ainda Waldow; Borges e Segatto (2006, p. 468), que:

As diferenças cognitivas geram os diferentes níveis de aprendizagem. Neste sentido, em uma mesma sala de aula existem níveis diferentes de aprendizagem e alunos que apresentam mais ou menos dificuldades de aprendizagem. O diagnóstico dessas dificuldades é individual, e deve ser feito com o intuito de descobrir qual ou quais os fatores estão afetando a cognição daquele sujeito.

Nesse sentido, nota-se que o processo de aprendizagem sofre interferência de vários fatores (intelectual, psicomotor, físico, social). Ele depende do esquema de ação inato do indivíduo, do estágio de maturação de seu sistema nervoso, do seu tipo psicológico constitucional e do seu grau de envolvimento esforço e interesse.

É importante destacar que em seu dia-a-dia o professor enfrenta vários desafios. Tal processo exige do professor uma constante busca de soluções aos problemas diários. Assim, quando não se busca tais soluções o processo de ensino-aprendizagem começa a apresentar deficiência (FERREIRA, 2005). No entanto, para que isto não ocorra é preciso que o professor esteja constantemente avaliando sua prática, atualizando seus planos de cursos e promovendo pesquisas, visando adquirir novos conhecimentos que possam ser utilizandos em sala de aula.

Os desafios enfrentados durante o processo de ensino aprendizagem podem ser superados (ou amenizados) com a utilização de estratégias de ensino, postas em prática por aqueles que de forma consciente, abraçam exercício do magistério, fazendo da prática docente uma força propulsora na construção da cidadania.

Isto porque "a formação escolar deve possibilitar aos alunos condições para desenvolver competência e consciência profissional" (BRASIL, 1997, p. 34), dando-lhe uma consciência crítica ao ponto de fazê-los sujeitos responsáveis por suas ações.

Assim sendo, os professores devem estar preparados para ensinar, para efetivamente exercer a sua função de educador, ajudando/orientar o aluno da melhor forma possível, evitando que o mesmo enfrente algum obstáculo no processo de ensino-aprendizagem no cotidiano escolar. Prática pedagógica é a forma de condução do ensino de um determinado 
tema. Na prática educativa, o professor tem um papel fundamental, ainda que ela não esteja centrada em suas ações, apenas dando pequenas orientações e fazendo observações. Por sua natureza, a prática pedagógica é algo complexo.

Contudo, afirmam Azambuja e Forster (2006, p. 3) que:

[...] a complexidade da atividade docente, não se limita a questão da instrução, ela envolve e contribui para a formação da personalidade, do espírito crítico e político dos indivíduos tanto no que se refere a sua dimensão individual, a sua relação consigo mesmo, quanto à sua dimensão coletiva.

Desta forma, entende-se que o professor deve ser um indivíduo preparado emocionalmente para produzir o conhecimento em sala de aula. Ele deve ser capaz de entender o comportamento e as ações de seus alunos, pois estes são pessoas e devem ser tratados com equidade. Em muitos casos, a prática docente pode contemplar atividades diferenciadas que muitas vezes transcendem os limites de uma sala de aula. Cabe ao educador definir metas e estratégias que poderão ser conjuntamente elaborados com os educandos visando à qualificação do ensino e do aprendizado (LIBÂNEO, 1994).

No entanto, o que se tem notado no contexto escolar é a utilização de uma prática pedagógica ultrapassada, denominada de 'tradicional', na qual, o professor limita todo o processo de aprendizagem ao livro didático, limitando, indiretamente, a aquisição de conhecimento por parte do próprio. Diante dessa realidade, percebe-se que é preciso o professore repensar sua prática.

Nesse sentido, observam Azambuja e Forster (2006, p. 4) que:

\begin{abstract}
Repensar a prática docente por meio da reflexão é possibilitar que se faça uso de um estoque de saberes constituintes da historicidade da vida de um professor, pois estes saberes permitem que o profissional identifique na prática o reconhecimento de situações únicas auxiliando-o a solucionar os problemas que emergem nesta por meio de sua bagagem experiencial.
\end{abstract}

Uma das formas de repensar a prática docente é o reconhecimento que a profissão docente exige uma formação constante, ou seja, exige capacitação periódica. Tal prática, "pode ser considerada como um meio de melhoramento não só das relações de trabalho, mas também do próprio trabalho onde se permite a produção, a busca e troca de saberes diferenciados aos habitualmente instituídos" (AZAMBUJA; FORSTER; 2006, p. 2).

Para romper com a prática tradicional da sala de aula, não adianta apenas a vontade do professor. É preciso que haja concepções teórico-metodológicas capazes de permitir o 
reconhecimento do saber do outro, a capacidade de ler o mundo da vida e reconhecer a sua dinamicidade, superando o que está posto como verdade absoluta. É preciso trabalhar com a possibilidade de encontrar formas de compreender o mundo, produzindo um conhecimento que é legítimo.

\section{Metodologia}

O presente estudo foi de natureza descritiva, de caráter exploratório e possuiu uma abordagem quantitativa. A pesquisa foi desenvolvida durante o mês de setembro de 2016, objetivando avaliar as dificuldades apresentadas pelos professores. A pesquisa foi realizada na Escola Estadual de Ensino Fundamental Coriolano de Medeiros, localizada no Bairro Santo Antônio, na cidade de Patos, Estado da Paraíba.

O universo escolhido para realização desta pesquisa será o corpo docente da referida Escola Estadual. Para formar a amostra, de forma aleatória, foram escolhidos ao acaso 10 professores que exerciam suas atividades docentes na referida escola campo de pesquisa.

$\mathrm{Na}$ coleta dos dados, foi utilizado um questionário, previamente elaborado, contendo questões subjetivas, relacionadas aos objetivos da pesquisa. Após a coleta, os dados foram analisados de forma quantitativamente, oportunidade em que se utilizou do modelo descritivo. Os referidos dados após analisados foram apresentados em Gráficos e posteriormente comentados à luz da literatura pertinente.

\section{Resultados e Discussão}

A princípio, procurou-se saber dos professores entrevistados como se apresenta o ensino em suas escolas. O Gráfico 1, a seguir, relaciona as respostas obtidas nesse quesito.

\section{Gráfico 1 - Distribuição da amostra quanto à opinião sobre como} se apresenta o ensino em sua escola

\begin{tabular}{|c|c|c|}
\hline $70 \%$ & $60 \%$ & \multirow{2}{*}{$\begin{array}{l}\text { Ainda de forma livresco, } \\
\text { valorizando a memorização } \\
(n=4)\end{array}$} \\
\hline $50 \%$ & \multirow[b]{2}{*}{$40 \%$} & \\
\hline & & \multirow{6}{*}{$\begin{array}{l}\text { Completo, porque o } \\
\text { conhecimento apresentado } \\
\text { pelos professores, possui } \\
\text { conexão com a realidade } \\
\text { cotidiana do aluno }(\mathrm{n}=6)\end{array}$} \\
\hline $40 \%$ & & \\
\hline $30 \%$ & & \\
\hline $20 \%$ & & \\
\hline $10 \%$ & & \\
\hline $0 \%$ & & \\
\hline
\end{tabular}


Quando se analisa os dados contidos no Gráfico 1 verifica-se que 60\% dos professores entrevistados acham que o ensino desenvolvido em sua escola pode ser considerado completo, porque o conhecimento apresentado pelos professores possui uma conexão com a realidade vivenciada em seu dia a dia pelo aluno $(n=6)$. Contudo, na observação de $40 \%$ dos professores que participaram da presente pesquisa $(n=4)$, esse ensino se mostra ainda de forma livresco, valorizando a memorização e a repetição de formas.

Na opinião de Souza e Barros (2012, p. 2):

O livro didático é uma das fontes de informações para o ensino. O professor pode e deve fazer uso de diversos outros recursos didáticos para o processo de aprendizagem do aluno, em que encontrem uma maior interação entre os alunos e os conteúdos estudados.

Para que haja aprendizagem significativa, o ensino não deve se limitar ao livro didático, evitando, assim, ser transformado num ensino livresco. Para enriquecer esse ensino, o professor pode e deve sempre utilizar de outros recursos, fazendo o possível para estabelecer uma correlação entre o conteúdo e o 'mundo' do aluno, contextualizando, assim, o ensino.

O Gráfico diz respeito ao fato se os professores entrevistados enfrentam ou não alguma dificuldade em sua sala de aula, no cotidiano escolar.

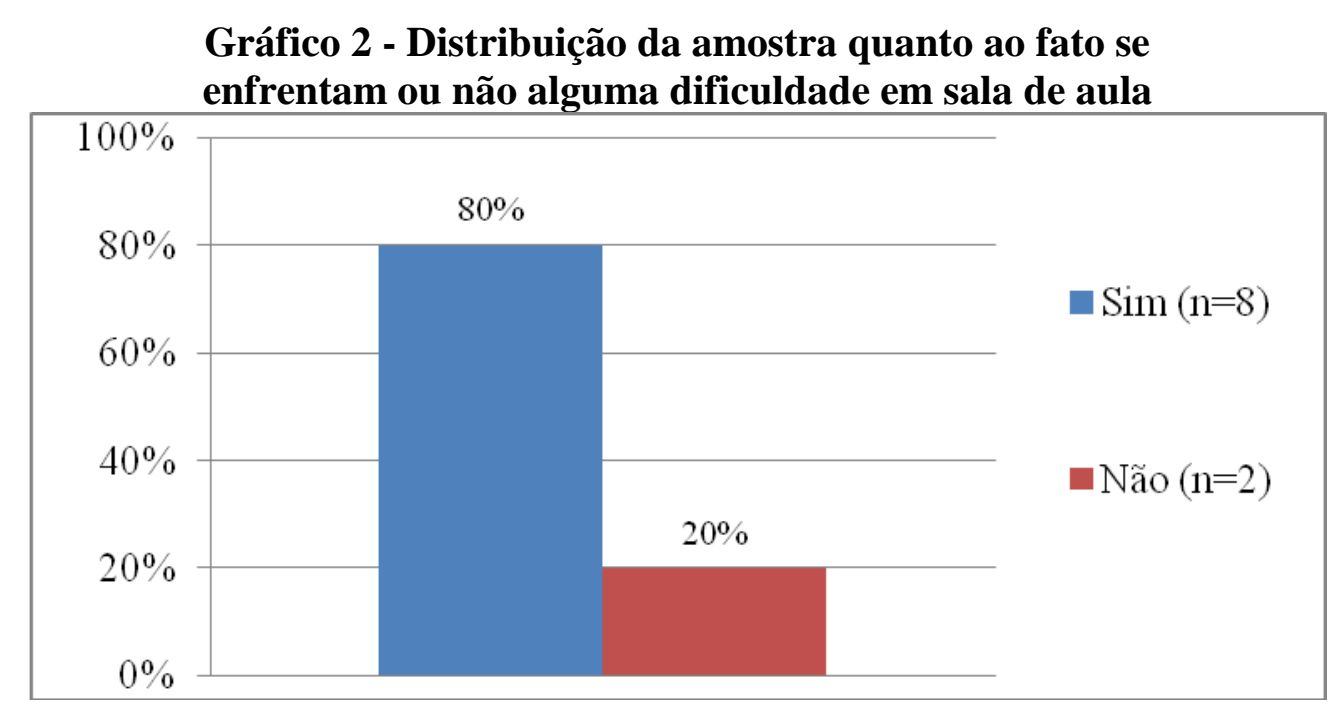

Os dados demonstrados no Gráfico 2 revelam que $80 \%$ dos professores entrevistados, em seu dia a dia, enfrentam dificuldades em sua sala de aula. No entanto, $20 \%$ declararam que não enfrentam.

Na concepção de Najle e Fiamenghi JR (2007, p. 99): 
Os professores têm enfrentado muita dificuldade em seu trabalho, pois os alunos não se sentem motivados para aprender, alguns querem apenas conversar com os colegas, outros escutam música, além de apresentar comportamentos agressivos e, muitas vezes, violentos em relação aos professores. Muitos professores ficam angustiados e até perdem o controle, sem saber o que fazer. Assim os próprios professores desestimulam-se para ensinar, ficam sem desejo para trabalhar e acabam por perder o interesse para com a aprendizagem do aluno.

Deve-se reconhecer que reconhecer que o sempre estará sujeito a enfrentar dificuldades no contexto da sala aula, por várias razões. Entretanto, é de suma importância que o professor saiba lidar com essa situação e desenvolver esforços no sentido de superar tais dificuldades.

O Gráfico 3 apresenta os tipos de dificuldades enfrentadas pelos professores entrevistados em seu dia a dia na escola.

\section{Gráfico 3 - Distribuição da amostra quanto ao que estão ligadas} as dificuldades em sala de aula

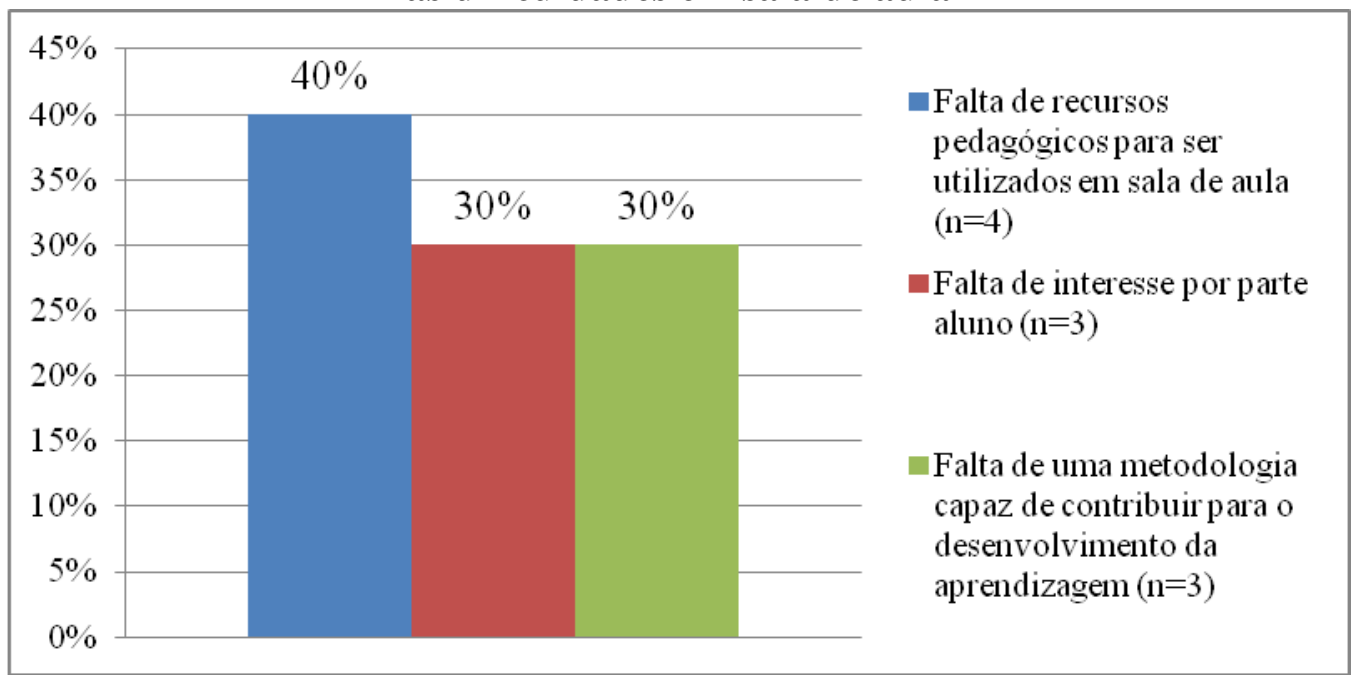

Quando se analisa dos dados apresentados no Gráfico 3 verifica-se que $40 \%$ dos participantes informaram que a dificuldades enfrentadas em sala de aula, dizem respeito à falta de recursos pedagógicos para ser utilizados em sala de aula $(\mathrm{n}=5), 30 \%$ correlacionaram à falta de uma metodologia capaz de contribuir para o desenvolvimento da aprendizagem $(n=3)$ e outros $30 \%$ informaram que a dificuldade enfrentada diz respeito à falta de interesse por parte aluno $(n=3)$.

Segundo Costoldi et al (2009, p. 2), “os recursos didáticos são de fundamental importância no processo de desenvolvimento cognitivo do aluno, uma vez que proporciona uma maior oportunidade de aprendê-lo de forma mais efetiva, onde o aluno poderá aproveitar esse conhecimento por toda a vida". 
Assim sendo, se uma escola não possui recursos didáticos para auxiliar no processo de ensino aprendizagem, essa falta passa a constitui-se numa dificuldade à educação. Por outro lado, se falta uma metodologia capaz de contribuir para o desenvolvimento da aprendizagem, esta realidade demonstra a necessidade de uma formação continuada, para que os professores entrevistados passassem a ter uma melhor prática pedagógica. E, consequentemente, tenham condições de superar as dificuldades que enfrentam em sala de aula.

Nesse sentido, Souza (2007, p. 111) afirma que:

O professor deve ter formação e competência para utilizar os recursos didáticos que estão ao seu alcance e muita criatividade, ou ate mesmo construir junto com seus alunos, pois, ao manipular esses objetos a criança tem possibilidade de aprender melhor esses conteúdos. Os recursos didáticos não devem ser utilizados de qualquer jeito, deve haver um planejamento por parte do professor, que deverá saber como utilizá-lo para alcançar o objetivo proposto por sua disciplina.

Desta forma, atuar em sala de aula o professor precisa, além da formação, ter competência, criatividade e ser aberto para aprender. Ele precisa saber conhecer/identificar as limitações de seus alunos para assim, selecionar as melhores metodologias que deverão ser utilizadas em sala de aula. Sem essa capacidade, ele enfrentará sempre dificuldades.

Posteriormente, perguntou-se aos professores da escola que serviu de campo para a presente pesquisa, se eles procuram desenvolver em sala de aula atividades criativas objetivando motivar seus alunos. Os dados apresentados no Gráfico 4, dizem respeito a esse questionamento.

Gráfico 4: Distribuição dos professores participantes quanto ao fato de desenvolver ou não atividades criativas objetivando motivar seus alunos

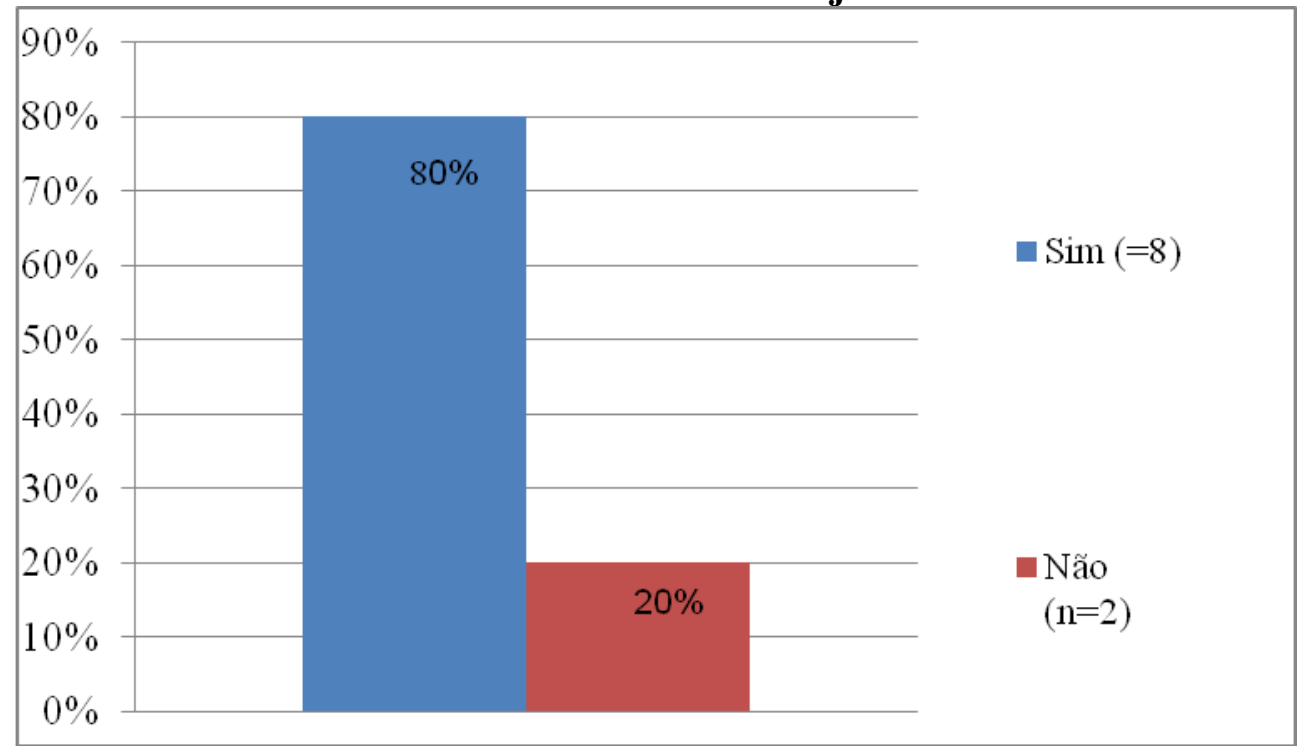


Quando se analisa os dados contidos no Gráfico 4, verifica-se que $20 \%$ dos professores entrevistados não procuram desenvolver em sala de aula atividades criativas objetivando motivar seus alunos. No entanto, $80 \%$ utilizam-se da criatividade para motivar seus alunos.

Infirma Azambuja e Forster (2006) que para desenvolver a criatividade em sala de aula requer atitudes especiais.

Não basta o professor ser um exímio conhecedor da matéria. Ele precisa ser altamente criativo e cooperador, inovando sempre a sua aula, utilizando metodologias que possam produzir uma aprendizagem significativa. Para tanto, o professor precisa reunir habilidades para motivar o aluno, ensinando-o a pensar e a se tornar autônomo.

Por outro lado, destaca Sanches (2004) que quando o professor não possui condições de inovar sua sala, ele pode desmotivar seus alunos, transformando sua aula em algo chato e cansativo.

Assim, o professor deve abandonar o método expositivo tradicional, em que o papel dos alunos é quase sempre passivo e procurar seguir o método ativo, estabelecendo diálogo com os alunos e estimulando a imaginação destes, de modo produzir uma melhor aprendizagem.

Os dados colhidos com o último questionamento feito aos professores encontram-se apresentados no Gráfico 7 que diz respeito ao que deve ter o professor para ser considerado como criativo.

Gráfico 7 - Distribuição da amostra quanto ao que deve ter o professor para ser considerado como criativo

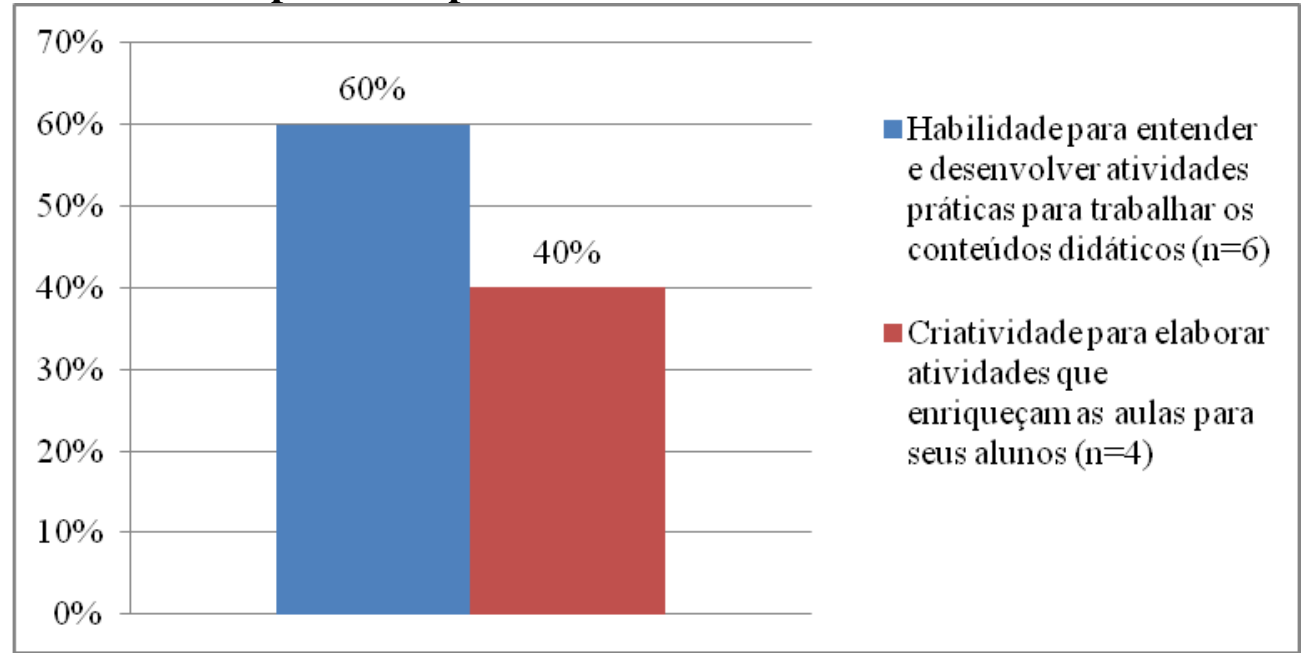


Analisando o Gráfico 7 verifica-se que de acordo com 60\% dos professores entrevistados, para que um professor seja considerado como criativo ele deve possuir habilidades para desenvolver atividades práticas para trabalhar os conteúdos em sala de aula $(n=6)$. No entanto, $40 \%$ acham que é preciso ter criatividade para elaborar atividades que enriqueçam as aulas para seus alunos $(n=4)$.

Segundo Oliveira e Alencar (2008, p. 297):

O docente para obter êxitos no trabalho criador em sala de aula terá que ter inquietações científicas, estar sempre ávido de conhecer novos campos do saber, pensar criadoramente, respeitar os estudantes, sentir amor pela profissão, estar livre de formalismo, ter um alto sentido de organização e interesse pelo novo e estar estreitamente vinculado à prática diária da escola.

No processo educativo não se pode afirmar que um professor é criativo se ele não possuir habilidades para desenvolver atividades práticas para trabalhar os conteúdos em sala de aula e ao mesmo tempo for capaz de elaborar atividades que enriqueçam as aulas para seus alunos. Pois, a criatividade exige tudo isto. E, quanto maior for a capacidade do professor e promover intervenções dinâmicas, maior será o grau de criatividade.

\section{Conclusões}

Através da presente pesquisa pode-se constatar que a docência na Escola Estadual de Ensino Fundamental Coriolano de Medeiros vem se desenvolvendo de forma regular e que os professores da referida escola, ao desenvolverem suas aulas, tentam estabelecer uma conexão com a realidade vivenciada em seu dia a dia pelo aluno. E, que no exercício de suas funções os professores entrevistados enfrentam dificuldades, principalmente, pela falta de recursos pedagógicos para ser utilizados em sala de aula.

Constatou-se que na visão dos professores entrevistados, a criatividade é algo inovador que transforma o processo educativo e pode contribui para a melhoria do processo de ensino aprendizagem, exigindo habilidades por parte do professor para ser aplicada no contexto da sala de aula. Verificou-se também que entre os entrevistados existe o entendimento de que um professor criativo deve ter habilidade para entender e desenvolver atividades práticas para trabalhar os conteúdos didáticos. E, mais ainda, ele precisa saber elaborar atividades que enriqueçam as aulas para seus alunos.

\section{Referências}

AZAMBUJA, G. de; FORSTER, M. M. S. Diferentes dimensões da formação e da prática docente: culturas, representações e saberes. UNIrevista, v. 1, n. 2, p. 1-15, abr., 2006. 
BRASIL. Ministério da Educação. Secretaria de Educação Fundamental. Parâmetros Curriculares Nacionais: introdução. Brasília, 1997.

COSTOLDI, R.; POLINARSKI, C. A. Utilização de recursos didático-pedagógicos na motivação da aprendizagem. I Simpósio Internacional de Ensino e Tecnologia, Anais. Curitiba: UTFPR, 2009.

FERREIRA, L. S. Educação \& história. 2 ed. Ijuí, Editora Unijui, 2005.

LIBÂNEO, J. C. Didática. São Paulo: Cortez, 1994.

NAJLE, C. P. FIAMENGHI JR, G. A. Relação professores-alunos com dificuldades de aprendizagem e comportamento: história de mudanças. Cadernos de Pós-Graduação em Distúrbios do Desenvolvimento, v. 7, n. 1, p. 97-111, 2007.

OLIVEIRA, Z. M. F. de; ALENCAR, E. M. L. A criatividade faz a diferença na escola: o professor e o ambiente criativos. Contrapontos, v. 8, n. 2, p. 295-306, mai.-ago., 2008.

SANCHES, J. G. Dificuldades de aprendizagem e intervenção psicopedagógica. Porto Alegre: Artmed, 2004.

SOUZA, D. C. de; BARROS, M. D. de. Jogos interativos: uma possibilidade no ensino de ciências para a educação de jovens e adultos. III Encontro Nacional de Ensino de Ciências da Saúde e do Ambiente, 2012. Anais, Niterói/RJ: UFF, 2012.

SOUZA, S. E. O uso de recursos didáticos no ensino escolar. In: I Encontro de Pesquisa em Educação. IV Jornada de Prática de Ensino, XIII Semana de Pedagogia da UEM: Infância e Práticas Educativas. Arq Mudi, v. 11, n. 2, p. 19-26, 2007.

WALDOW, C.; BORGES, G.; SEGATTO, K. Dificuldades de aprendizagem: possibilidades de superação fazendo arte. Synergismus Scyentifica, n. 1, v. 1-4, p. 1-778, 2006. 